\title{
Francisella recognition by inflammasomes: differences between mice and men
}

\section{Mikhail A. Gavrilin* and Mark D. Wewers*}

Division of Pulmonary, Allergy, Critical Care and Sleep Medicine, Davis Heart and Lung Research Institute, The Center for Microbial Interface Biology, The Ohio State University, Columbus, OH, USA

\section{Edited by:}

Amal Amer, The Ohio State University, USA

\section{Reviewed by:}

Amal Amer, The Ohio State University, USA

lain Lamont, University of Otago,

New Zealand

\section{${ }^{*}$ Correspondence:}

Mikhail A. Gavrilin and Mark D. Wewers,

Pulmonary, Allergy, Critical Care and

Sleep Medicine, Davis Heart and Lung

Research Institute, 473 West 12th

Avenue, Columbus, OH 43210, USA.

e-mail:gavrilin.1@osu.edu;

wewers.2@osu.edu
Pathogen recognition by intracellular sensors involves the assembly of a caspase-1 activation machine termed the inflammasome. Intracellular pathogens like Francisella that gain access to the cytosolic detection systems are useful tools to uncover the details of caspase-1 activation events. This review overviews Francisella function in the mononuclear phagocyte with particular attention to inflammasome versus pyroptosome roles and outlines differences between mouse and human caspase-1 activation pathways. Specific attention is placed on functional differences between human and murine pyrin as an intracellular recognition molecule for Francisella.

Keywords: AIM2, Francisella, IL-1ß, inflammasome, M-CSF, monocytes, pyrin, pyroptosome

\section{OVERVIEW}

Understanding the innate host response to infectious challenges is a process greatly accelerated by the discovery of intracellular pathogen sensors and the inflammasome concept, reviewed extensively in this special edition. Much can be learned by focusing on the details of individual pathogen types, which can refine our understanding of innate host functions. In this mini-review, we will focus on the detection of Francisella and how this particular organism has allowed a clearer understanding of intracellular pathogen recognition. We will also briefly review Francisella infection and the peculiarities regarding detection in mouse and man.

Francisella tularensis is a zoonotic agent circulating in the Northern Hemisphere. It is transmitted from host to host by several pathways where arthropod vectors predominate (Ellis et al., 2002; Sjostedt, 2007). F. tularensis represents four subspecies differing in geographical location, infectivity, and virulence to the various hosts (Oyston, 2008). The most virulent species is F. tularensis subsp. tularensis (F. tularensis) with median lethal dose $<10$ CFU for humans, mice, and rabbits. However, F. tularensis subsp. holarctica ( $F$. holarctica) has more broad virulence with calculated LD50 ranging from $\sim 1 \mathrm{CFU}$ for mice, $<10^{3} \mathrm{CFU}$ for humans, and $>10^{6} \mathrm{CFU}$ for rabbits. F. tularensis subsp. novicida (F. novicida) while still highly virulent in mice $\left(\mathrm{LD} 50<10^{3} \mathrm{CFU}\right)$, shows low virulence for humans and rabbits (reviewed in Ellis et al., 2002).

Abbreviations: AIM2, absent in melanoma 2; ASC, apoptosis-associated speck-like protein containing a CARD; CARD, caspase recruitment domain; DAMP, danger-associated molecular pattern; NLR, NOD-like receptor (nucleotide-binding domain, leucine-rich repeat containing protein); NLRC, NOD-like receptor containing a CARD; NLRP, NOD-like receptor containing a PYD; PAMP, pathogen associated molecular pattern; PRR, pattern recognition receptor; PYD, pyrin domain; RIG-I, retinoic acid inducible gene I.
The disease caused by F. tularensis is called tularemia, otherwise known as rabbit fever (Ellis et al., 2002). The characteristics of tularemia include fever, aches, and signs of toxicity lasting for several days (Parmely et al., 2009). If left untreated, tularemia may result in high mortality, reaching up to $60 \%$ with the pneumonic form of the disease (reviewed in Parmely et al., 2009).

Because Francisella has a low dose requirement, high virulence, and high morbidity, it is an attractive organism for bacteriological weapons (Sjostedt, 2007). Since F. tularensis was included in the list of select agents as a potential bioterrorist weapon (Ellis et al., 2002; Rotz et al., 2002), research into the pathogenicity of this bacteria in host organisms has been greatly accelerated. Large data sets have been generated regarding the specific details of bacteria-host interactions, albeit with some controversy. The controversy may be explained by differences in models used, including Francisella subspecies, host organisms, or cell types.

Francisella belongs to a select group of bacteria, including Listeria, Shigella, Burkholderia, and Rickettsia spp., which proliferate within the host cell cytosol (Ray et al., 2009). Francisella evolved to replicate in macrophages, which function to provide the first line of defense against pathogens. To survive in this biological niche, Francisella developed a strategy to avoid recognition and destruction by the immune system in order to utilize the host resources and multiply. The employment of this strategy by different $F$. tularensis subspecies dictates the differences in bacterial pathogenicity and evolutionary success.

Accordingly, a delay in recognition and immune system activation should be beneficial. F. tularensis (Schu4, type A) is the most virulent subspecies for both mice and humans, suppressing all pro-inflammatory responses for at least $72 \mathrm{~h}$ following infection (Kirimanjeswara et al., 2008). Since the Schu4 strain requires a BSL3 facility, more work has been done with the less virulent 
strains, F. holarctica (LVS, type B) and F. novicida. However, these two subspecies differ in their relative virulence for mice versus human - i.e., virulent in mice and attenuated in humans.

Could this difference in virulence be related to distinctions in recognition? Based on differences in virulence between Francisella subspecies and host organisms, it is reasonable to suggest that differences in Francisella recognition are based upon host response differences. Notably, virulent and attenuated Francisella subspecies have escape capacities that drive release from the phagosome in both humans and mice (Golovliov et al., 2003; Mariathasan et al., 2005; Gavrilin et al., 2006). Upon phagosomal escape Francisella may be also recognized by intracellular pathogen sensors, many of which belong to the NLR family of proteins. The focus of current review is to highlight Francisella recognition by different hosts.

\section{INFLAMMASOME VERSUS PYROPTOSOME INFLAMMASOME}

Francisella recognition induces fever and cell death and is characterized by a wave of pro-inflammatory cytokines, where IL-1 $\beta$ plays a major role. This cytokine is induced upon mononuclear cell stimulation and synthesized as a biologically inactive proIL-1 $\beta$ (Dinarello, 1998). Its conversion to the biologically active $17 \mathrm{kDa}$ form, which includes cleavage and release from cells, is tightly regulated by caspase- 1 which, in turn, also requires an activation event (Yamin et al., 1996). Caspase-1 activation depends upon assembly of a multiprotein complex called the inflammasome (Martinon et al., 2002). All protein partners in the inflammasome possess either CARD (caspase recruitment domain) or PYD (pyrin domain) and assemble via CARD-CARD and PYD-PYD interactions (Martinon and Tschopp, 2006; Martinon et al., 2009). The prototypical inflammasome consists of CARD containing caspase-1, CARD, and PYD containing adaptor molecule ASC, and an NLR sensor of pathogen- or danger-associated molecule patterns (PAMPs or DAMPs). Depending on the presence of CARD or PYD domains, these sensors are subdivided as NLRC or NLRP family members, respectively (Ting et al., 2008). Because caspase- 1 is the central protein/component of every inflammasome, while ASC is present in the majority of them, inflammasomes are named based on the participating pattern recognition receptor PRR (NLR or other CARD or PYD containing protein). As such, several inflammasome structures have been described. These include the NLRP1 inflammasome (NLRP1, ASC, caspase-1, and caspase-5; Martinon et al., 2002), the NLRP3 inflammasome (NLRP3, CARD8, ASC, caspase-1; Agostini et al., 2004), the NLRC4 (IPAF) inflammasome (NLRC4, ASC, caspase-1; Mariathasan et al., 2004), and the NLRC5 inflammasome (NLRC5, ASC, caspase-1; Davis et al., 2010). However, it was proposed that several non-NLR proteins may also initiate the assembly of inflammasomes. For example, the RIG-I inflammasome (RIG-I, ASC, caspase-1; Poeck et al., 2010), the AIM2 inflammasome (AIM2, ASC, caspase-1; Burckstummer et al., 2009; Fernandes-Alnemri et al., 2009; Hornung et al., 2009; Roberts et al., 2009), and the pyrin inflammasome (pyrin, ASC, caspase-1; Yu et al., 2006; Gavrilin et al., 2009).

\section{PYROPTOSOME}

In addition to the widely accepted inflammasome concept, there is another caspase- 1 activation platform, which may be distinct from the inflammasome, called a pyroptosome (Fernandes-Alnemri et al., 2007). The pyroptosome is a single (one per cell) $1-2 \mu \mathrm{m}$ supra-molecular speck which contains ASC and caspase-1. This speck is different from the in vitro reconstituted inflammasome, which forms a ring-like structure with an outer diameter of $\sim 13 \mathrm{~nm}$ and an inner diameter of $\sim 4 \mathrm{~nm}$ (Faustin et al., 2007). Pyroptosome assembly is associated with host cell death that occurs within minutes of the ASC speck complex formation (FernandesAlnemri et al., 2007). This type of cell death is uniquely dependent on caspase- 1 activation and, because of its ability to induce IL-1 $\beta$ dependent fever, named pyroptosis (Fink and Cookson, 2005). Host cell pyroptosis results in ASC pyroptosome aggregation, followed by cell rupture and the accompanied release of IL-1 $\beta$ (FernandesAlnemri et al., 2007). However, IL-1 $\beta$ and caspase- 1 accumulation in cell culture media is often seen in the absence of cell death following LPS or bacterial infection of mononuclear phagocytes which suggests that inflammasomes may be distinct from pyroptosomes (Mangan et al., 1991; Gavrilin et al., 2009; Santic et al., 2010). In this regard, at least some of the IL- $1 \beta$ and caspase-1 (as well as ASC and some other PRR) are released from live monocytes in the form of microvesicles (MacKenzie et al., 2001; Sarkar et al., 2009). Since the size of exosomal microvesicles is $80-100 \mathrm{~nm}$, these inflammasomes are likely distinct from the micrometer sized pyroptosome. Thus, pyroptosome formation accompanying pyroptosis may be a radically different way to eliminate a cytosolic bacterial burden compared to microvesicular IL- $1 \beta$ and the inflammasome release pathway. How host cell death is regulated by caspase- 1 and how it may differ with respect to caspase- 1 activation pathways is an area of particular interest for future studies. The summary of the inflammasome versus pyroptosome is shown in Table $\mathbf{1 .}$

\section{MURINE RECOGNITION OF INTRACELLULAR FRANCISELLA INTERFERON SIGNALING}

It is clear in mice that type I interferon signaling is necessary for inflammasome activation, IL-1 $\beta / \mathrm{IL}-18$ release, and the extensive cell death that follows Francisella infection (Henry et al., 2007). Murine macrophages showed $10^{3}$-fold increase of If $n b$ mRNA $8 \mathrm{~h}$ after infection with F. novicida (Henry et al., 2007). The 100-fold induction of the If $n b$ gene was also observed after mouse macrophage infection with the LVS Francisella strain, but in contrast to Illb gene expression which peaks at $4 \mathrm{~h}$ post-infection, induction of the Ifnb gene

Table 1 | Pyroptosome versus inflammasome.

\begin{tabular}{lll}
\hline & Pyroptosome & Inflammasome \\
\hline Localization & Intracellular & Intra and extra-cellular \\
Size & $1000-2000 \mathrm{~nm}$ & $13 \mathrm{~nm}$ \\
Cell death & ++ & + \\
Inflammation & + & ++ \\
ASC & + & + \\
PRR & + & + \\
Caspase-1 & + & + \\
ProlL-1 $\beta$ processing & + & +
\end{tabular}

Reference Cheng et al. (2010), Cookson and Brennan (2001), Fernandes-Alnemri and Alnemri (2008), Fernandes-Alnemri et al. (2007), Jones et al. (2010)

Faustin et al. (2007), Gavrilin et al. (2009), Kahlenberg and Dubyak (2004), Martinon et al. (2002), Sarkar et al. (2009), Zhou et al. (2010) 
was observed much later (starting at $12 \mathrm{~h}$ post-infection; Cole et al., 2008). In response to intracellular Francisella, mouse macrophages secrete IFN- $\beta$, which in an autocrine fashion activates caspase- 1 and induces extensive cell death (Henry et al., 2007). In a paracrine fashion, IFN- $\beta$ negatively regulates the number of IL-17A(+) gamma delta T cells and resistance to infection (Henry et al., 2010). However, while many researchers agree that IFN- $\beta$ activates the inflammasome, there is a controversy surrounding its effect on the expression of some potential Francisella-sensing PRR. In particular, it was reported that Aim 2 expression is either induced (Jones et al., 2010) or not affected (Alnemri, 2010; Fernandes-Alnemri et al., 2010) in murine macrophages by IFN- $\beta$ treatment. Thus, IFN- $\beta$ 's role in inflammasome function requires additional study.

\section{AIM2 AS FRANCISELLA-SENSING PRR}

Knockout animals provide an extremely powerful tool to evaluate the effects of specific innate molecules on biological processes. In experiments with knockout mice, the importance of the caspase-1/ ASC axis activation following Francisella escape into the cytosol was clearly shown (Mariathasan et al., 2005). It was also shown that in mice Nlrp1, Nlrp3, and Nlrc4 do not recognize Francisella (Weiss et al., 2007; Huang et al., 2010). Recently, several groups showed that absent in melanoma 2 (Aim2), an interferon-inducible protein, is responsible for intracellular Francisella detection in murine macrophages (Fernandes-Alnemri et al., 2010; Jones et al., 2010; Rathinam et al., 2010). Aim2 belongs to the HIN-200 (PYHIN) protein family (Ludlow et al., 2005). Mice and humans share 55\% amino acid identity of Aim2 (Choubey et al., 2010). Structurally, Aim2 has a HIN-200 amino acid repeat, which can bind double strand DNA, and a PYD domain, which is able to homo-dimerize with other PYD domains (Burckstummer et al., 2009; Choubey et al., 2010). The PYD domain of Aim2 may recruit the PYD of the inflammasome adaptor ASC, as shown by co-localization after dual co-expression (Burckstummer et al., 2009). This co-localization is functional, as over-expression of mouse Aim 2 induces ASC-dependent activation of an $N F-\kappa B$ reporter gene (Rathinam et al., 2010) and promotes caspase- 1 activation (Fernandes-Alnemri et al., 2009). When Aim2 is expressed in the cell, ASC oligomerization is induced by variety of factors, such as double stranded DNA (Burckstummer et al., 2009; Fernandes-Alnemri et al., 2009; Roberts et al., 2009). Thus, Aim2ASC-caspase-1 may form an Aim2 inflammasome or pyroptosome, whereas bacterial DNA serves as the DAMP which induces this assembly. In support of this conclusion, it was recently shown that F. novicida and LVS strains activate murine caspase-1 in an Aim2 dependent manner (Fernandes-Alnemri et al., 2010; Jones et al., 2010; Rathinam et al., 2010). Caspase- 1 activation, IL-1 $\beta$ secretion, and cell death were absent in Aim2 $2^{-1-}$ macrophages in response to F. novicida infection (Fernandes-Alnemri et al., 2010), while bacterial burden was increased (Jones et al., 2010). It is proposed that bacterial DNA could leak into the cytoplasm during escape from the phagosome as a result of Francisella lysis and phagosome acidification (Fernandes-Alnemri et al., 2010). Thus far, there is no consensus as to whether the Aim2-ASC speck represents the inflammasome or the pyroptosome. To avoid confusion, some researchers refer to the speck as an "ASC focus," with the belief that assembly of this focus leads to secretion of mature IL-1 $\beta$ and cell death (Jones et al., 2010).

\section{INTRACELLULAR FRANCISELLA RECOGNITION IN HUMAN PHAGOCYTES INTERFERON SIGNALING AND AIM2 EXPRESSION}

Although Aim2 is clearly important in murine responses to Francisella, the process of Francisella recognition in human mononuclear cells is less clear. In sharp contrast to the mouse macrophages, infection of human monocytes with attenuated F. novicida does not lead to the up-regulation of type I interferon signaling (Butchar et al., 2008). However, virulent F. tularensis Schu4 induce some IFNB gene expression (Butchar et al., 2008). At the same time, $F$. novicida induces significantly higher IL-1 $\beta$ release in human monocytes compared to Schu4 or LVS (Gavrilin et al., 2006; Butchar et al., 2008). Of note, we are unable to find detectable expression of AIM2 in primary human CD14+ monocytes by Western blot (unpublished results). However, it has been shown that human PBMC express detectable amounts of AIM2 (Meixenberger et al., 2010). Human AIM2 gene is expressed in the spleen, small intestine, and peripheral leukocytes (DeYoung et al., 1997). Because PBMC contain lymphocytes as well as CD14+ monocytes, lymphocyte contributions may explain this difference in AIM2 detection. Also, in agreement with our data are reports that human monocytes do not express AIM2 except after interferon induction (Hornung et al., 2009; Rathinam et al., 2010). However, the inability of F. novicida to induce IFN- $\beta$ in human monocytes (Butchar et al., 2008), may explain the failure to detect human monocyte AIM2. Concomitantly, human monocytes release large amounts of mature IL- $1 \beta$ following infection with F. novicida, suggesting that human monocytes may utilize a PRR other than AIM2 for intracellular Francisella recognition (Gavrilin et al., 2009). Interestingly, Francisella-infected human CD14+ monocytes show high induction of interferon gamma gene (IFNG), i.e., type II interferon signaling (Butchar et al., 2008). This induction may represent a defense mechanism by which IFN- $\gamma$ restricts cytosolic growth of Francisella without affecting its phagosomal escape (Edwards et al., 2010). Of note, it was shown that IFN- $\gamma$ also may induce AIM2 expression in human monocytic cell line THP-1 (Fernandes-Alnemri et al., 2009) as well as pyrin in human CD14+ monocytes (Centola et al., 2000).

\section{PECULIARITIES OF PYRIN FUNCTION IN HUMAN VERSUS MURINE CELLS}

Pyrin, the familial Mediterranean fever (FMF) protein, belongs to the tripartite motif (TRIM) family of proteins, all of which share structural homology (Nisole et al., 2005). Although pyrin has an amino terminal PYD, it is not a member of NLR family of intracellular sensors of pathogens. Nonetheless, pyrin has been shown to interact via its PYD with the adaptor protein ASC (Richards et al., 2001). Importantly, the CARD of the ASC molecule can interact directly with caspase- 1 via the amino terminal CARD. As a result, these proteins could assemble into an inflammasome. We observed that pyrin, ASC, and caspase-1, tagged to various fluorescent proteins and expressed in HEK 293 cells, co-localize into one speck (unpublished data), which is similar to the AIM2 pyroptosome discussed earlier.

The hypothetical model of pyrin inflammasome with its C-terminal B30.2 domain as a pathogen sensor was first proposed by Alnemri and colleagues (Yu et al., 2006). Importantly, this lab showed that the Mefv knockout animals still respond to F. novicida, whereas Aim2 ${ }^{-1-}$ animals do not (Fernandes-Alnemri 
et al., 2010). This implies that Aim2, but not pyrin, is responsible for Francisella-induced caspase- 1 activation and IL-1 $\beta$ release in murine macrophages.

Our work suggests that the human response to Francisella may be quite distinct from the murine response. For example, pyrin is an important component of caspase- 1 activation and IL- $1 \beta$ release after challenging human mononuclear cells with $F$. novicida (Gavrilin et al., 2009). At first glance, this result is difficult to reconcile with the Mefv murine knockout results (Fernandes-Alnemri et al., 2010). However, it is important to highlight an important difference between pyrin protein coded by $M E F V$ in human and mice (Figure 1). Although these two species share $47.6 \%$ identity and $65.5 \%$ similarity in pyrin amino acid sequence, murine pyrin lacks the complete B30.2 domain, a potential pathogen sensing region (Chae et al., 2000). Importantly, mutations responsible for FMF in humans are mostly located in the B30.2 domain (Ting and Davis, 2005). Thus, it is possible that mice have lost their ability to detect Francisella via pyrin due to genetic changes in murine pyrin gene.

Pyrin's role in caspase- 1 function has also been a subject of controversy. Discovered as a gene mutation that leads to bouts of inflammation, several groups immediately suggested an antiinflammatory role for pyrin by showing that pyrin can inhibit IL-1 $\beta$ activation (Chae et al., 2003, 2006; Papin et al., 2007). In contrast, other groups provide evidence that pyrin is a pro-inflammatory protein, activating caspase- 1 dependent IL-1 $\beta$ cleavage (Yu et al., 2006, 2007; Seshadri et al., 2007; Gavrilin et al., 2009). Working with human primary CD14+ monocytes and their derived macrophages, we observed a correlation between pyrin levels and the ability of the cell to process and release IL-1 $\beta$ in response to Francisella infection. Fresh human monocytes show high levels of pyrin and readily release large quantities of IL-1 $\beta$, whereas macrophages are relatively deficient in pyrin and defective in processing, but not in the synthesis of proIL-1 $\beta$. Alveolar macrophages also follow this pattern and do not readily process and release IL- $1 \beta$ (Wewers and Herzyk, 1989). In addition, the modulation of intracellular pyrin levels in mononuclear phagocytes in various stages of differentiation correlates with the ability of pyrin to affect IL- $1 \beta$ release in response to Francisella infection (Gavrilin et al., 2006, 2009; Seshadri et al., 2007).
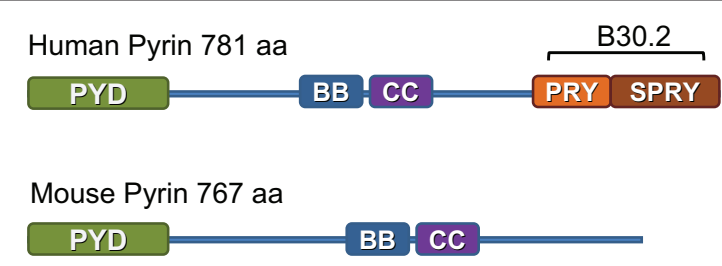

\begin{tabular}{ll}
\hline PYD & PAAD/DAPIN/Pyrin domain \\
BB & B-Box-type zinc finger; zinc binding domain \\
CC & Coiled-coil domain \\
PRY & PRY domain, associated with SPRY domain \\
SPRY & SPRY domain
\end{tabular}

FIGURE 1 | Differences between pyrin in human and mice.

\section{M-CSF}

Particularly noticeable is the striking effect of M-CSF on pyrin levels in human cells. Macrophages matured in the presence of M-CSF maintain pyrin levels and readily release IL-1 $\beta$ followed by infection with Francisella, similar to freshly harvested CD14+ human monocytes. Moreover, macrophages matured in the absence of growth factors, while defective in proIL- $1 \beta$ processing and release, re-induce pyrin and the ability to process IL- $1 \beta$ with M-CSF treatments (Gavrilin et al., 2009). Thus, the local microenvironment may modulate a broad-range of macrophage phenotypes that extend well beyond M1/M2 classification models.

\section{THP-1 CELL LINE AS A MODEL OF HOST-PATHOGEN INTERACTION}

In discussing the differences in AIM2 and pyrin expression and function between mice and primary human mononuclear cells, it is important to mention the human pre-monocytic cell line THP-1 because a plethora of experiments have been performed with this cell line. THP-1 cells are phagocytic, can be infected with Francisella, and show activation of caspase-1 (Mohapatra et al., 2007; Zakharova et al., 2010). It was shown that stimulation of THP-1 cells with PMA, Sendai virus, or INF- $\gamma$ induces AIM2 expression (Burckstummer et al., 2009; Fernandes-Alnemri et al., 2009; Hornung et al., 2009). PMA treated THP- 1 cells also release IL-1 $\beta$ after infection with F. novicida. During THP-1 differentiation to THP-derived macrophages (TDM), pyrin disappears as is also observed with CD14+ monocyte differentiation to monocyte-derived macrophages (MDM). Consistent with a role for pyrin in caspase- 1 activation after F. novicida, TDMs transduced to express pyrin release about sixfold more IL-1 $\beta$ upon infection with F. novicida as compared to TDM controls (Gavrilin et al., 2009). Nevertheless, even in the absence of pyrin, TDM release more IL-1 $\beta$ than do fresh THP-1 cells, suggesting the existence of a non-pyrin activation mechanism as well. Thus, it is interesting to speculate that pyrin and AIM2 may both be sensors of Francisella and that these two sensors may work in concert with each other. This speculation is more important in human cells with fully intact pyrin B30.2 domains.

In keeping with the pyrin/AIM2 dual detection hypothesis, it is notable that each PRR may recognize certain DAMP or PAMP covering discreet molecular patterns, such that overlapping regions of recognition may lead to more precise detection of pathogen types. The example of such composite detection is shown for Listeria, where mouse Nlrc4, Nlrp3, and Aim2 work in cooperation (Tsuchiya et al., 2010; Warren et al., 2010; Wu et al., 2010) while human PBMC appear to detect Listeria only via NLRP3 and not in cooperation with AIM2, NLRC4, and other tested NLRs (Meixenberger et al., 2010). The newly described NLRC5 inflammasome also demonstrated cooperativity with NLRP3 when THP-1 cells were stimulated with panel of PAMPs and DAMPs, typically activating NLRP3 inflammasome (Davis et al., 2010).

Regarding Francisella detection, we cannot rule out the possibility that AIM2 expression in human monocytes exists below the limits of confident detection, but still in amounts sufficient to trigger ASC oligomerization and caspase-1 activation upon DNA recognition. Apparently, NLRs may be able to act at low concentrations relative to ASC and caspase-1, triggering an initial node of activation. For example, NLRP3 initiates ASC pyroptosome oligomerization at the molar ratio of 1:500 (Fernandes-Alnemri et al., 2007). Following 
initial dimerization, ASC oligomerization may become independent of NLR requirements, having reached a critical threshold concentration (Cheng et al., 2010). Yet, maximum caspase- 1 activity using an in vitro reconstructed inflammasome was shown at molar ratio of caspase-1: ASC-NALP1 as 2:1:1 (Faustin et al., 2007). Thus, much remains to be learned about the mechanisms that drive inflammasome and pyroptosome formation and function.

\section{CONCLUSION}

In summary, the study of specific pathogens continues to uncover particulars of inflammasome regulation. In the case of Francisella, human mononuclear cells recognize Francisella before its internalization resulting in activation of multiple signaling pathways, including proIL-1 $\beta$ synthesis. Thus intracellular Francisella, after escape from the phagosome, may be detected by several pattern

\section{REFERENCES}

Agostini, L., Martinon, F., Burns, K., McDermott, M. F., Hawkins, P.N., and Tschopp, J. (2004). NALP3 forms an IL-1beta-processing inflammasome with increased activity in MuckleWells autoinflammatory disorder. Immunity 20,319-325.

Alnemri,E. S. (2010). Sensing cytoplasmic danger signals by the inflammasome. J. Clin. Immunol. 30, 512-519.

Burckstummer, T., Baumann, C., Bluml, S., Dixit, E., Durnberger, G., Jahn, H., Planyavsky, M., Bilban, M., Colinge, J., Bennett, K. L., and Superti-Furga, G. (2009). An orthogonal proteomicgenomic screen identifies AIM2 as a cytoplasmic DNA sensor for the inflammasome. Nat. Immunol. 10, 266-272.

Butchar, J. P., Cremer, T. J., Clay, C. D., Gavrilin, M. A., Wewers, M. D., Marsh, C. B., Schlesinger, L. S., and Tridandapani, S. (2008). Microarray analysis of human monocytes infected with Francisella tularensis identifies new targets of host response subversion. PLoS ONE3, e2924. doi: 10.1371/ journal.pone.0002924

Centola, M., Wood, G., Frucht, D. M., Galon, J., Aringer, M., Farrell, C., Kingma, D. W., Horwitz, M. E., Mansfield, E., Holland, S. M., O'Shea, J. J., Rosenberg, H. F., Malech, H. L., and Kastner, D. L. (2000). The gene for familial Mediterranean fever, MEFV, is expressed in early leukocyte development and is regulated in response to inflammatory mediators. Blood 95 , 3223-3231.

Chae, J. J., Centola, M., Aksentijevich, I., Dutra, A., Tran, M., Wood, G., Nagaraju, K., Kingma, D. W., Liu, P. P., and Kastner, D. L. (2000). Isolation, genomic organization, and expression analysis of the mouse and rat homologs of MEFV, the gene for familial mediterranean fever. Mamm. Genome 11, 428-435.
Chae, J. J., Komarow, H. D., Cheng, J., Wood, G., Raben, N., Liu, P. P., and Kastner, D. L. (2003). Targeted disruption of pyrin, the FMF protein, causes heightened sensitivity to endotoxin and a defect in macrophage apoptosis. Mol. Cell 11, 591-604.

Chae,J.J., Wood, G., Masters, S. L., Richard, K., Park, G., Smith, B. J., and Kastner, D. L. (2006). The B30.2 domain of pyrin, the familial Mediterranean fever protein, interacts directly with caspase-1 to modulate IL-1beta production. Proc. Natl. Acad. Sci. U.S.A. 103, 9982-9987.

Cheng, J., Waite, A. L., Tkaczyk, E. R., Ke, K., Richards, N., Hunt, A. J., and Gumucio, D. L. (2010). Kinetic properties of ASC protein aggregation in epithelial cells. J. Cell. Physiol. 222, 738-747.

Choubey, D., Duan, X., Dickerson, E., Ponomareva, L., Panchanathan, R., Shen, H., and Srivastava, R. (2010). Interferon-inducible p200-family proteins as novel sensors of cytoplasmic DNA: role in inflammation and autoimmunity. J. Interferon Cytokine Res. 30, 371-380.

Cole, L. E., Santiago, A., Barry, E., Kang, T. J., Shirey, K. A., Roberts, Z. J., Elkins, K. L., Cross, A. S., and Vogel, S. N. (2008). Macrophage proinflammatory response to Francisella tularensis live vaccine strain requires coordination of multiple signaling pathways. J. Immunol. 180, 6885-6891.

Cookson, B. T., and Brennan, M.A. (2001). Pro-inflammatory programmed cell death. Trends Microbiol. 9, 113-114.

Davis, B. K., Roberts, R. A., Huang, M. T., Willingham, S. B., Conti, B. J., Brickey, W. J., Barker, B. R., Kwan, M., Taxman, D. J., Accavitti-Loper, M. A., Duncan, J. A., and Ting, J. P. (2010). Cutting edge: NLRC5-dependent activation of the inflammasome. J. Immunol. $186,1333-1337$.

DeYoung, K. L., Ray, M. E., Su, Y. A., Anzick, S. L., Johnstone, R. W.,

recognition receptors, where AIM2 and pyrin may trigger formation of the pyroptosome or the inflammasome platform for caspase-1 activation. This event results in the initiation of cell death and/or IL- $1 \beta$ processing and release. However, comparisons between mice and humans reveal that there are important evolutionary changes in pathogen sensing that are likely to have been driven by environmental pressures. Understanding the peculiarities of pathogen host sensing is dependent upon powerful animal models but must continue to be interpreted along side of human studies.

\section{ACKNOWLEDGMENTS}

This work was supported by the NIH/NIAID Regional Center of Excellence for Bio-defense and Emerging Infectious Diseases Research (RCE) Program U54-AI-057153, by NIH HL089440 and HL76278.

Trapani, J. A., Meltzer, P. S., and Trent, J. M. (1997). Cloning a novel member of the human interferoninducible gene family associated with control of tumorigenicity in a model of human melanoma. Oncogene 15, 453-457.

Dinarello, C.A. (1998). Interleukin-1 beta, interleukin-18, and the interleukin-1 beta converting enzyme. Ann. N. Y. Acad. Sci. 856, 1-11.

Edwards, J.A., Rockx-Brouwer, D., Nair, V. and Celli, J.(2010). Restricted cytosolic growth of Francisella tularensis subsp. tularensis by IFN-gamma activation of macrophages. Microbiology 156, 327-339.

Ellis, J., Oyston, P. C., Green, M., and Titball, R. W. (2002). Tularemia. Clin. Microbiol. Rev. 15, 631-646.

Faustin, B., Lartigue, L., Bruey, J. M. Luciano, F., Sergienko, E., BaillyMaitre, B., Volkmann, N., Hanein, D., Rouiller, I., and Reed, J. C. (2007). Reconstituted NALP1 inflammasome reveals two-step mechanism of caspase-1 activation. Mol. Cell 25, 713-724.

Fernandes-Alnemri, T., and Alnemri, E. S. (2008). Assembly, purification, and assay of the activity of the ASC pyroptosome. Meth. Enzymol. 442, 251-270.

Fernandes-Alnemri, T., Wu, J., Yu, J. W., Datta, P., Miller, B., Jankowski, W., Rosenberg, S., Zhang, J., and Alnemri, E. S. (2007). The pyroptosome: a supramolecular assembly of ASC dimers mediating inflammatory cell death via caspase-1 activation. Cell Death Differ. 14, 1590-1604.

Fernandes-Alnemri, T., Yu, J. W., Datta, P., Wu, J., and Alnemri, E. S. (2009). AIM2 activates the inflammasome and cell death in response to cytoplasmic DNA. Nature 458, 509-513.

Fernandes-Alnemri, T., Yu, J. W., Juliana, C., Solorzano, L., Kang, S., Wu, J., Datta, P., McCormick, M., Huang, L.,
McDermott, E., Eisenlohr, L., Landel, C. P., and Alnemri, E. S. (2010). The AIM2 inflammasome is critical for innate immunity to Francisella tularensis. Nat. Immunol. 11, 385-393.

Fink, S. L., and Cookson, B. T. (2005). Apoptosis, pyroptosis, and necrosis: mechanistic description of dead and dying eukaryotic cells. Infect. Immun. 73, 1907-1916.

Gavrilin, M. A., Bouakl, I. J., Knatz, N. L., Duncan, M. D., Hall, M. W., Gunn, J. S., and Wewers, M. D. (2006). Internalization and phagosome escape required for Francisella to induce human monocyte IL-1beta processing and release. Proc. Natl. Acad. Sci. U.S.A. 103, 141-146.

Gavrilin, M. A., Mitra, S., Seshadri, S., Nateri, J., Berhe, F., Hall, M. W., and Wewers, M. D. (2009). Pyrin critical to macrophage IL-1beta response to Francisella challenge. J. Immunol. 182, 7982-7989.

Golovliov, I., Baranov, V., Krocova, Z., Kovarova,H., and Sjostedt,A. (2003).An attenuated strain of the facultative intracellular bacterium Francisella tularensis can escape the phagosome of monocytic cells. Infect. Immun. 71, 5940-5950.

Henry, T., Brotcke, A., Weiss, D. S. Thompson, L. J., and Monack, D. M. (2007). Type I interferon signaling is required for activation of the inflammasome during Francisella infection. J. Exp. Med. 204, 987-994.

Henry, T., Kirimanjeswara, G. S., Ruby, T., Jones, J. W., Peng, K., Perret, M., Ho, L., Sauer, J. D., Iwakura, Y., Metzger, D. W., and Monack, D. M. (2010). Type I IFN signaling constrains IL-17A/F secretion by gammadelta $\mathrm{T}$ cells during bacterial infections. J. Immunol. 184, 3755-3767.

Hornung, V., Ablasser, A., CharrelDennis, M., Bauernfeind, F., Horvath, G., Caffrey, D. R., Latz, E., and Fitzgerald, K. A. (2009). AIM2 recognizes cytosolic dsDNA and forms a 
caspase-1-activating inflammasome with ASC. Nature 458, 514-518.

Huang, M. T., Mortensen, B. L., Taxman, D. J., Craven, R. R., Taft-Benz, S., Kijek, T. M., Fuller, J. R., Davis, B. K., Allen, I. C., Brickey, W. J., Gris, D., Wen, H., Kawula, T. H., and Ting, J. P. (2010). Deletion of ripA alleviates suppression of the inflammasome and MAPK by Francisella tularensis. J. Immunol. 185, 5476-5485.

Jones, J. W., Kayagaki, N., Broz, P., Henry, T., Newton, K., O’Rourke, K., Chan, S., Dong, J., Qu, Y., Roose-Girma, M., Dixit, V. M., and Monack, D. M. (2010). Absent in melanoma 2 is required for innate immune recognition of Francisella tularensis. Proc. Natl. Acad. Sci. U.S.A. 107, 9771-9776.

Kahlenberg, J. M., and Dubyak, G. R. (2004). Mechanisms of caspase- 1 activation by $\mathrm{P} 2 \mathrm{X} 7$ receptor-mediated $\mathrm{K}+$ release.Am. J. Physiol. Cell Physiol. 286, C1100-C1108.

Kirimanjeswara, G. S., Olmos, S., Bakshi, C. S., and Metzger, D. W. (2008). Humoral and cell-mediated immunity to the intracellular pathogen Francisella tularensis. Immunol. Rev. 225, 244-255.

Ludlow, L. E., Johnstone, R. W., and Clarke, C. J. (2005). The HIN-200 family: more than interferon-inducible genes? Exp. Cell Res. 308, 1-17.

MacKenzie, A., Wilson, H. L., Kiss-Toth, E., Dower, S. K., North, R. A., and Surprenant,A. (2001). Rapid secretion of interleukin-1beta by microvesicle shedding. Immunity 15, 825-835.

Mangan, D. F., Welch, G. R., and Wahl, S. M. (1991). Lipopolysaccharide, tumor necrosis factor-alpha, and IL-1 beta prevent programmed cell death (apoptosis) in human peripheral blood monocytes. J. Immunol. 146, 1541-1546.

Mariathasan, S., Newton, K., Monack, D. M., Vucic, D., French, D. M., Lee, W. P., Roose-Girma, M., Erickson, S., and Dixit, V. M. (2004). Differential activation of the inflammasome by caspase- 1 adaptors ASC and Ipaf. Nature 430, 213-218.

Mariathasan, S., Weiss, D. S., Dixit, V. M., and Monack, D. M. (2005). Innate immunity against Francisella tularensis is dependent on the ASC/caspase-1 axis. J. Exp. Med. 202, 1043-1049.

Martinon, F., Burns, K., and Tschopp, J. (2002). The inflammasome: a molecular platform triggering activation of inflammatory caspases and processing of proIL-beta. Mol. Cell 10, 417-426.

Martinon, F., Mayor, A., and Tschopp, J. (2009). The inflammasomes: guardians of the body. Annu. Rev. Immunol. 27, 229-265.

Martinon, F., and Tschopp, J. (2006). Inflammatory caspases and inflammasomes: master switches of inflammation. Cell Death Differ. 14, $10-22$.

Meixenberger, K., Pache, F., Eitel, J., Schmeck, B., Hippenstiel, S., Slevogt, H., N'Guessan, P., Witzenrath, M., Netea, M. G., Chakraborty, T., Suttorp, N., and Opitz, B. (2010). Listeria monocytogenes-infected human peripheral blood mononuclear cells produce IL-1beta, depending on listeriolysin $\mathrm{O}$ and NLRP3. J. Immunol. 184, 922-930.

Mohapatra, N. P., Balagopal, A., Soni, S., Schlesinger, L. S., and Gunn, J. S. (2007). AcpA is a Francisella acid phosphatase that affects intramacrophage survival and virulence. Infect. Immun. 75, 390-396.

Nisole, S., Stoye, J. P., and Saib, A. (2005). TRIM family proteins: retroviral restriction and antiviral defence. Nat Rev. Microbiol. 3, 799-808.

Oyston, P. C. (2008). Francisella tularensis: unravelling the secrets of an intracellular pathogen. J. Med. Microbiol. 57, 921-930.

Papin, S., Cuenin, S., Agostini, L., Martinon, F., Werner, S., Beer, H. D., Grutter, C., Grutter, M., and Tschopp, J. (2007). The SPRY domain of pyrin, mutated in familial Mediterranean fever patients, interacts with inflammasome components and inhibits proIL-1beta processing. Cell Death Differ. 14, 1457-1466.

Parmely, M. J., Fischer, J. L., and Pinson, D. M. (2009). Programmed cell death and the pathogenesis of tissue injury induced by type A Francisella tularensis. FEMS Microbiol. Lett. 301, 1-11.

Poeck, H., Bscheider, M., Gross, O., Finger, K., Roth, S., Rebsamen, M. Hannesschlager, N., Schlee, M., Rothenfusser, S., Barchet, W., Kato, H., Akira, S., Inoue, S., Endres, S., Peschel, C., Hartmann, G., Hornung, V., and Ruland, J. (2010). Recognition of RNA virus by RIG-I results in activation of CARD9 and inflammasome signaling for interleukin 1 beta production. Nat. Immunol. 11, 63-69.

Rathinam, V.A., Jiang, Z., Waggoner, S. N., Sharma, S., Cole, L. E., Waggoner, L., Vanaja, S. K., Monks, B. G., Ganesan, S., Latz, E., Hornung, V., Vogel, S. N., Szomolanyi-Tsuda, E., and Fitzgerald, K.A. (2010). The AIM2 inflammasome is essential for host defense against cytosolic bacteria and DNA viruses. Nat. Immunol. 11, 395-402.

Ray, K., Marteyn, B., Sansonetti, P. J., and Tang, C. M. (2009). Life on the inside: the intracellular lifestyle of cytosolic bacteria. Nat. Rev. Microbiol. 7, 333-340.

Richards, N., Schaner,P., Diaz,A., Stuckey, J., Shelden, E., Wadhwa, A., and Gumucio, D. L. (2001). Interaction between pyrin and the apoptotic speck protein (ASC) modulates ASC-induced apoptosis. J. Biol. Chem. 276, 39320-39329.

Roberts, T. L., Idris, A., Dunn, J. A., Kelly, G. M., Burnton, C.M., Hodgson, S., Hardy, L. L., Garceau, V., Sweet, M. J., Ross, I. L., Hume, D. A., and Stacey, K. J. (2009) HIN-200 proteins regulate caspase activation in response to foreign cytoplasmic DNA. Science 323, 1057-1060.

Rotz, L. D., Khan, A. S., Lillibridge, S. R., Ostroff, S. M., and Hughes, J. M. (2002). Public health assessment of potential biological terrorism agents. Emerging Infect. Dis. 8, 225-230.

Santic, M., Pavokovic, G., Jones, S., Asare, R., and Kwaik, Y.A. (2010). Regulation of apoptosis and anti-apoptosis signalling by Francisella tularensis. Microbes Infect. 12, 126-134.

Sarkar, A., Mitra, S., Mehta, S., Raices, R. and Wewers, M. D. (2009). Monocyte derived microvesicles deliver a cell death message via encapsulated caspase-1. PLoS ONE 4, e7140. doi: 10.1371/journal.pone.0007140

Seshadri, S., Duncan, M. D., Hart, J. M., Gavrilin, M. A., and Wewers M. D. (2007). Pyrin levels in human monocytes and monocyte-derived macrophages regulate IL-1beta processing and release. J. Immunol. $179,1274-1281$.

Sjostedt, A. (2007). Tularemia: history, epidemiology, pathogen physiology, and clinical manifestations. Ann. N. Y. Acad. Sci. 1105, 1-29.

Ting, J. P., and Davis, B. K. (2005) CATERPILLER: a novel gene family important in immunity, cell death, and diseases. Annu. Rev. Immunol. 23, 387-414.

Ting, J. P., Lovering, R. C., Alnemri, E. S., Bertin, J., Boss, J. M., Davis, B. K. Flavell, R. A., Girardin, S. E., Godzik, A., Harton, J. A., Hoffman, H. M., Hugot, J. P., Inohara, N., Mackenzie, A., Maltais, L. J., Nunez, G., Ogura, Y., Otten, L. A., Philpott, D., Reed, J. C., Reith, W. Schreiber, S., Steimle, V., and Ward, P.A (2008). The NLRgene family: a standard nomenclature. Immunity 28, 285-287.

Tsuchiya, K., Hara, H., Kawamura, I. Nomura, T., Yamamoto, T., Daim, S. Dewamitta, S. R., Shen, Y., Fang, R., and Mitsuyama, M. (2010). Involvement of absent in melanoma 2 in inflammasome activation in macrophages infected with Listeria monocytogenes. J. Immunol. 185, 1186-1195.

Warren, S. E., Armstrong, A., Hamilton, M. K., Mao, D. P., Leaf., I. A., Miao E. A., and Aderem, A. (2010). Cutting edge: cytosolic bacterial DNA activates the inflammasome via Aim2. Immunol. 185, 818-821.

Weiss, D. S., Henry, T., and Monack D. M. (2007). Francisella tularensis activation of the inflammasome. Ann. N. Y. Acad. Sci. 1105, 219-237.

Wewers, M. D., and Herzyk, D. J. (1989). Alveolar macrophages differ from blood monocytes in human IL-1 beta release. Quantitation by enzyme-linked immunoassay. J. Immunol. 143, 1635-1641.

Wu, J., Fernandes-Alnemri, T., and Alnemri, E. S. (2010). Involvement of the AIM2, NLRC4, and NLRP3 inflammasomes in caspase- 1 activation by Listeria monocytogenes. J. Clin. Immunol. 30, 693-702.

Yamin, T. T., Ayala, J. M., and Miller, D. K. (1996). Activation of the native 45-kDa precursor form of interleukin1-converting enzyme. J. Biol. Chem. 271, 13273-13282.

Yu, J. W., Fernandes-Alnemri, T., Datta, P., Wu, J., Juliana, C., Solorzano, L., McCormick,M.,Zhang,Z., and Alnemri, E. S. (2007). Pyrin activates the ASC pyroptosome in response to engagement by autoinflammatory PSTPIP1 mutants. Mol. Cell 28, 214-227.

Yu, J. W., Wu, J., Zhang, Z., Datta, P., Ibrahimi, I., Taniguchi, S., Sagara, J., Fernandes-Alnemri, T., and Alnemri, E. S. (2006). Cryopyrin and pyrin activate caspase-1, but not NF-kappaB, via ASC oligomerization. Cell Death Differ. 13, 236-249.

Zakharova, E., Grandhi, J., Wewers, M. D., and Gavrilin, M. A. (2010) Mycoplasma suppression of THP-1 cell TLR responses is corrected with antibiotics. PLoS ONE 5, e9900. doi: 10.1371/journal.pone.0009900

Zhou, R., Yazdi, A. S., Menu, P., and Tschopp, J. (2010). A role for mitochondria in NLRP3 inflammasome activation. Nature 469, 221-225.

Conflict of Interest Statement: The authors declare that the research was conducted in the absence of any commercial or financial relationships that could be construed as a potential conflict of interest.

Received: 16 November 2010; paper pending published: 28 December 2010; accepted: 19 January 2011; published online: 09 February 2011

Citation: Gavrilin MA and Wewers MD (2011) Francisella recognition by inflammasomes: differences between mice and men. Front. Microbio. 2:11. doi: 10.3389/ fmicb.2011.00011

This article was submitted to Frontiers in Cellular and Infection Microbiology, a specialty of Frontiers in Microbiology. Copyright (c) 2011 Gavrilin and Wewers. This is an open-access article subject to an exclusive license agreement between the authors and Frontiers Media SA, which permits unrestricted use, distribution, and reproduction in any medium, provided the original authors and source are credited. 